\title{
Perfiles
}

ROODY RÉSERVE

\section{Haití: doscientos años de sueños frustrados}

En el primer día del año 2004, la República de Haití celebraba sus doscientos años de vida independiente. Hace exactamente dos siglos que triunfó la revuelta de los esclavos, la primera y única victoria de este estilo en el mundo. Se consagró la libertad de los negros y mulatos de Saint Domingue y la independencia política de este rincón de tierra. Aquel $1^{\circ}$ de enero de 1804 , en la plaza de armas de Gonaïves, no sólo se consagró la victoria definitiva de los haitianos sobre las poderosas fuerzas armadas de Napoleón, sino que se ratificó la voluntad de unos excluidos de hacer realidad su reivindicación por la igualdad, el respeto y los derechos de todos los seres humanos. Si Francia fue la cuna de la declaración de los derechos humanos inalienables de las personas, Haití es el primer lugar donde se planteó la necesidad de que éstos fueran universales, sin restricción de razas, de color o de linaje.

Es necesario recordar el contexto político, económico y social del mundo de esa época para comprender a cabalidad el significado histórico de aquella inolvidable gesta. Francia, Inglaterra, España y, en menor medida, Portugal y Holanda, no obstante sus rivalidades de naciones que se disputaban la hegemonía en Europa, gozaban alegremente de sus colonias en América y otras partes del planeta, de las cuales sacaban enormes ganancias para financiar sus sangrientas gue- 
rras y mantener el nivel de vida de sus habitantes. Gracias a la exportación de azúcar - $y$, en menor medida, el café-, cuya importancia en esa época algunos igualan a la del petróleo en nuestros días, esta pequeña porción de territorio de la isla Hispaniola, actualmente conocida como Haití, se convirtió en la Colonia más rica del mundo. Desde allí se generaban una tercera parte de todas los bienes de exportación de la Francia de aquella época. Al final del siglo 17, por ejemplo, se estima que el valor las exportaciones de Saint Domingue superaba al de los Estados Unidos.

Esa prosperidad de la que disfrutaban alegremente Francia y sus representantes en la Colonia, sin embargo, condenaba a una existencia infrahumana a más de seiscientas mil personas, los esclavos, las bestias de carga sobre las que reposaba el sistema colonial. Algunos testimonios sobre la época recuerdan el sufrimiento y el desastre humano que supuso la esclavitud. Los esclavos trabajaban de sol a sol, en condiciones infrahumanas para mantener la rentabilidad de las haciendas de los blancos. Por ejemplo, uno de los catalizadores de la revuelta que culminará en la independencia de Haití fue la exigencia incesante de los esclavos porque se hiciera realidad un decreto del rey de Francia que estipulaba un día de descanso para los esclavos de las plantaciones.

En este contexto, en 1791 inició la gran revuelta que hubo de culminar en la independencia de Saint Domingue. En la noche del 14 de agosto de ese año, en una localidad conocida como Bois Caiman, Boukman, uno de los pioneros en la lucha por la libertad de los esclavos, reunió en un acto político simbólico a decenas de esclavos para reivindicar sus derechos humanos, su identidad cultural y su derecho a vivir en libertad. Hizo la siguiente declaración: «Escuchen al Dios que ha hecho el sol que brilla sobre nosotros, que mueve la mar y que truena en el cielo. Este Dios que nos mira desde las nubes, observa lo que nos hacen los blancos. El dios de los blancos pide el crimen, mientras que el nuestro pide cosas buenas. Pero, nuestro Dios que es tan bueno nos ordena vengarnos. Dirigirá nuestros brazos y nos asistirá en la faena. Boten las imágenes del dios de los blancos sediento de nuestro sudor y escuchen la libertad que habla en nuestro corazón».

A partir de lo sucedido en aquella noche, conocida históricamente como la Ceremonia del Bois Caiman, la lucha por la libertad de los 
esclavos tomó un giro trascendental. Los negros empezaron a creer en sí mismos y en su capacidad de derrotar la opresión. La sencillez de esta afirmación no debe ocultar la densidad de su contenido. Hay que recordar que todo el sistema colonial esclavista reposaba sobre una auténtica desposesión de la identidad a los esclavizados. De esta manera, se aseguraba la docilidad de estos últimos. Así, muchos llegaron a aceptar de manera fatalista su condición de bestias de cargas, simples herramientas al servicio de la prosperidad de la colonia.

Entre los muchos temas regulados en el famoso Code Noir, la legislación referente a la vida de los esclavos en las plantaciones, publicado en 1685 por Louis XIV, debe reseñarse las disposiciones relacionadas con el despojo de la identidad a los esclavos. Se estipula que todo recién llegado a las colonias debe ser bautizado. Así, el africano se convertía en Negro, cambiaba de nombre, era privado del derecho a usar su propia lengua y era forzado a abandonar sus costumbres alimenticias y vestimentarias. Luego era marcado por un hierro incandescente y mandado al trabajo servil. No es extraño que luego de más de dos siglos sobreviviendo en estas condiciones infrahumanas que muchos esclavos llegaran a asumir la ideología de sus verdugos y asumir su condición de seres inferiores.

Con estos antecedentes, se resalta el valor histórico, cultural y político del discurso de Boukman en el Bois Caiman. Entendió que el único camino para derrotar la esclavitud pasaba por una reapropiación de la identidad negada, profundamente enraizada en las tradiciones africanas. Así, la liberación de Haití se hizo desde los valores propios, inspirados en la religión y tradiciones ancestrales de los esclavos. Finalmente, después de 13 años de lucha, se logró la expulsión definitiva de los representantes franceses en la colonia y se selló la derrota del sistema esclavista.

Toussaint L'ouverture y Jean Jacques Dessalines son los dos principales artífices de esta gesta. El primero no vio la independencia. Dos años antes, en 1802, había sido capturado y deportado a Francia por el general Leclerc, el cuñado de Napoleón, al mando del ejército de restauración del dominio francés en la isla. Murió de frío en la fortaleza de Joux. Sin embargo, Toussaint es reconocido mundialmente como el Espartaco negro. En 1801, después de sucesivas alianzas con los británicos, los españoles y los franceses, aprovechando las 
rivalidades de unos contra los otros, había declarado la autonomía completa de la isla. Hizo publicar la primera constitución de Saint Dominque en donde dejó consagrada la libertad e igualdad de todos los habitantes, negros, mulatos y blancos, del territorio. Por eso, declaró solemnemente después de su arresto y deportación a Francia que tan sólo se había cortado el tronco del árbol de la libertad de los negros. Sin embargo, éste seguiría floreciendo, porque sus raíces son profundas y numerosas.

En efecto, Jean Jacques Dessalines, retomó enseguida la lucha por la libertad. Luego de combates encarnizados, el ejército de harapientos (los que van descalzos, dice una expresión francesa), mal entrenados y mal equipados, derrotaron a la expedición de más de cuarenta y tres mil soldados, enviado por Napoleón para restablecer el orden -entiéndase la esclavitud- en las colonias. Noticias de la época recuerdan que tan sólo unos pocos lograron salir con vida de Saint Domingue. En estas circunstancias, se declaró la independencia de Haití, con la siguiente proclama de los principales jefes de los rebeldes: «Juramos, ante la posteridad y a todo el universo, renunciar por siempre a Francia y morir, antes que vivir bajo su dominación». Saint Domingue pasó a llamarse Haití, tierras altas, en lenguaje de los indígenas, los primeros habitantes de la isla, exterminados en las minas de oro durante los primeros años de la conquista española.

Luego de la independencia se hicieron sucesivos esfuerzos por lograr la unificación de toda la isla. Francia tan sólo controlaba una tercera parte de la isla, el territorio que España le había cedido en 1697, luego de la firma del tratado de Ryswick. Sin embargo, debido a la inestabilidad política y social crónica conjugada con la incapacidad de encontrar un cauce institucional al problema de los antagonismos raciales, no se pudo hacer efectiva la unificación. Los dominicanos recuerdan aún con cierta indignación los 25 años de ocupación sangrienta del gobierno de Jean Pierre Boyer, el último que logró mantener a toda la isla bajo una única autoridad. Los dominicanos terminarían pidiendo la protección de España, en contra de las aspiraciones hegemónicas de sus vecinos haitianos.

En estas circunstancias, muy pronto se empezaron a romper los sueños de unidad, prosperidad, y de igualdad de esta primera República de antiguos esclavos. Duró muy poco el buen entendimiento 
-cuya importancia se reafirma en el lema de la República: «la unión hace la fuerza"-entre los distintos componentes de la sociedad. Dessalines, que se consagró como emperador de la República (en una imitación del poder del gobernante de Francia), fue traicionado por sus principales antiguos lugartenientes. Los generales Henri Christophe y Alexandre Pétion se aliaron para fomentar una rebelión en su contra. Cayó asesinado el 17 de octubre de 1806, en el lugar conocido como Pont Rouge. Christophe se hizo del control de la parte norte del país, en donde establecerá una monarquía que durará hasta 1820 , la fecha de su muerte. De la experiencia de su gobierno, Alejo Carpentier encontraría la inspiración de su famosa novela El Reino de este mundo, iniciador del realismo maravilloso como género literario. Petion, en cambio, se estableció en el oeste y en el sur desde donde fundó una República de mulatos.

Las circunstancias de la muerte de Dessalines cristalizan todas las batallas políticas que se han librado en el país desde la independencia hasta nuestros días. Desde el inicio, «el padre de la patria» se opuso a las ambiciones desmedidas de los mulatos quienes querían apropiarse de las plantaciones dejadas por los blancos, por considerarse herederos «naturales» de los antiguos propietarios. Dessalines se autodenominó el padre de todos los haitianos, especialmente de los antiguos esclavos, cuyos padres están en Africa, incapaces de presentar títulos de propiedad o de exhibir relación de sangre alguna con los blancos expulsados. Debido a su negativa a avalar la exclusión de los más humildes se fraguó su asesinato. La ambición de poder por parte de sus compañeros de armas conspiró en contra de su gobierno.

Desde esa fecha, la inestabilidad política se instaló en la recién liberada República. Si bien se abolió la esclavitud, se estableció de hecho una especie apartheid social y económica. A raíz del asesinato de Dessalines, los mulatos, descendientes de los blancos, terminaron de hacerse con el control económico. Los campesinos, antiguos esclavos, gentes de las montañas, quedaron marginados y excluidos. De vez en cuando se acudía a ellos - como lo atestigua la convulsionada historia del país a lo largo de todo el siglo XIX-, como milicias armadas en la incesante lucha política sangrienta entre las elites negras y mulatas. La intervención armada de los Estados Unidos el 15 de julio de 1915 puso fin a este ciclo de inestabilidad. Después 19 años de ocupación, se creó la guardia nacional, particularmente espe- 
cializada en la represión política de los opositores y protectora de los intereses económicos de la burguesía local aliada, a su vez, con los grandes empresarios extranjeros.

La dictadura de 29 años de los Duvalier, iniciada con una victoria electoral el 22 sepriembre de 1957, se apoyó, al principio, en el sentimiento de exclusión de los ciudadanos negros, aún marginados por la elite mulata. Sin embargo, en 1986, cuando la población clamó por el fin del autoritarismo, no quedaba ya ningún elemento de reivindicación étnica en el poder corrupto y sanguinario de Jean Claude Duvalier. En todo caso, a esas alturas, ya se habían fusionado los intereses económicos de una elite negra, otrora resentida, con sus coetáneos blancos o mulatos. Pero, la gran mayoría de la población siguió sumida en la pobreza y el analfabetismo. Siguió imperando el divorcio entre unas elites -económicas y políticas-, cuyos referentes son el idioma francés, la cultura europea y el catolicismo, frente a una gran mayoría de ciudadanos, cuyo idioma es el creole, conserva sus herencias africanas, y practica el vudú.

Para iniciar la lucha por la emancipación general, Boukman apeló a los dioses ancestrales, la cultura autóctona y la identidad propia de los hijos de Africa. Después de la independencia, se impuso el francés como idioma oficial y, en beneficio de la Santa Iglesia Católica se prohibió el culto a los dioses africanos. El país navegó sin rumbo, perdido en una serie de luchas fratricidas que perduran hasta la fecha. La aceptación por parte de Occidente - “cuna de los países civilizados", se decía-se volvió una obsesión. Ninguna de las potencias mundiales de la época reconocieron la existencia de la nueva República. $\mathrm{Ni}$ los Estados Unidos, recién librados de la tutela de la Corona Británica, tenía demasiado interés en establecer relaciones diplomáticas con un grupo de negros insolentes. A decir verdad, no podría ser de otra manera. Para esa fecha, aún estaba en su pleno auge la segregación racial en ese país. Difícilmente se podría apoyar el esfuerzo de los antiguos esclavos haitianos, quienes en todo caso, habían sentado un precedente peligroso para los intereses de los grandes propietarios del norte.

En el subcontinente latinoamericano tampoco se notó algún entusiasmo de las nuevas Repúblicas en reconocer la gesta haitiana. Aunque, es necesario recordar que las autoridades políticas de Haití esta- 
ban dispuestas a colaborar con la causa independentista de los sublevados en contra de la dominación española en el continente. Por ejemplo, Francisco Javier Mina, uno de los pioneros en la lucha por la independencia de México, encontró buena acogida a su paso por la isla. Sernanas después de haber salido de Virginia llegó a Puerto Príncipe, el 27 de septiembre de 1816. Pétion, presidente de Haití a la sazón, le prestó ayudas para reparar sus fragatas. Varios marineros franceses, fugados de un barco de guerra de su país, reemplazaron a sus soldados que habían desertado. Permaneció un mes bajo la hospitalidad de Pétion y el 24 de noviembre del mismo año partió rumbo a la isla de Gálveston.

De igual manera, Miranda, procedente de Venezuela, fue recibido en Haití en 1806 por Dessalines que le proporcionó ayuda material, en armas y una impresora, y más de dos centenares de hombres con el objetivo de seguir su lucha por la liberación de esclavos en Venezuela, Colombia y Ecuador. Pocos saben, por ejemplo, que el origen de la bandera de Venezuela se encuentra en Jacmel, una ciudad haitiana, cuando Bolívar decidió poner en medio del azul y rojo de la bandera de Haití un pedazo de tela amarillo. Este último fue acogido en la ciudad de los cayos por el general Pétion quien lo ayudó en armas y municiones. Bolívar, al enterarse de la muerte de su benefactor, escribió a su sucesor Jean Pierre Boyer las siguientes emotivas líneas: «su patriotismo, su generosidad y las demás virtudes que lo caracterizaban han excitado mi veneración y la de todos mis compatriotas: esa veneración será tan inmortal como el nombre de Petión”.

No obstante, las muestras de una relación fluida entre las nuevas Repúblicas de América Latina y Haití se enfriaron con bastante rapidez. Por ejemplo, en 1826, con motivo del cónclave de unión de los países libres de la región que convocó Bolívar en Panamá, no se invitó a Estados Unidos ni a Haití por considerarlos uextranjeros a nuestros arreglos americanos». Al contrario, quiso que el Reino Unido se integrara a la liga hispanoamericana con el objetivo de defenderla del peligro de la reconquista española.

Así, otro de los problemas con que tuvo que lidiar la nueva República fue la falta de reconocimiento internacional. Francia interpretó con una perspicacia inusitada esta realidad. Desde el principio, empezo a presionar para volver a hacerse del control de su antigua colonia. Carlos X, el emperador de este entonces, militó por la extorsión de la 
nueva República. En 1838, Haití fue obligada a comprometerse a pagar una indemnización colectiva a todos los blancos expulsados o muertos durante la lucha por la independencia. El país tomará más de cincuenta años para pagar los noventa millones de franco/oro que supuso la deuda de la libertad adquirida. Mientras tanto, se tuvieron que postergar gastos importantes en la educación, la salud o, simplemente, el bienestar de los ciudadanos. Debido a las circunstancias en que se dio esa extorsión y lo que supuso en términos de sacrificios sociales, algunos ven ella el primer caso de ajuste estructural en el mundo.

Aún quedan muchas secuelas de la colonización. Doscientos años no han sido suficientes para cicatrizarse todas las heridas de la esclavitud. Desde un principio, las elites económicas se empeñaron a reproducir el mismo esquema de la dominación colonial. El pueblo expulsó a los franceses, algunos negros y mulatos tomaron su lugar. La gran mayoría de los haitianos siguen sintiéndose excluidos en su propio país. La desigualdad y la marginación social siguen campeando como en el tiempo de la colonia. Incluso en las luchas políticas se siguen encontrando eco de los clivajes raciales y económicos del pasado. En este inicio del siglo XXI, ninguno de los sueños de hace doscientos años se ha hecho realidad para los descendientes de los esclavos. Al contrario, en el bicentenario de su independencia, Haití se encuentra bajo la ocupación militar de Estados Unidos y Francia.

\section{Bibliografía}

Moise, Claude: Constitutions et luttes de pouvoir en Haiti, Les editions de CIDIHCA, Imprimerie Le Natal, Port-au-Prince, Haití, 1997. Métraux, Alfred: Le vaudou haitien, Éditions Gallimard, Paris, 1989 Carpentier, Alejo: El reino de este mundo, Seix Barral, Barcelona, 1978 Rapport au Ministre des affaires étrangeres, en: www. diplomatie.gouv.fr/actual/pdf/rapport_haiti.pdf

Haiti en: http://www.tlfq.ulaval.ca/axl/amsudant/haiti.htm 